\title{
Benign Vaginal Mixed Tumor
}

National Cancer Institute

\section{Source}

National Cancer Institute. Benign Vaginal Mixed Tumor. NCI Thesaurus. Code C40280.

A non-metastasizing, well circumscribed neoplasm that arises from the vagina and is characterized by the presence of a predominant benign mesenchymal component and benign glandular or squamous epithelial cells. 